\title{
Pendampingan Penyusunan Laporan Keuangan Koperasi dengan Menggunakan Excel di Lingkungan Kesra Perumnas Tanjung Karang Permai Mataram
}

\author{
Nur Fitriyah*, Herlina Pusparini, Nurabiah \\ Fakultas Ekonomi dan Bisnis, Universitas Mataram, Mataram, Indonesia
}

\section{Article history}

Received: 30-12-2020

Revised: 16-03-2021

Accepted: 18-06-2021

*Corresponding Author:

Nur Fitriyah,

Fakultas Ekonomi dan Bisnis,

Universitas Mataram,

Mataram, Indonesia;

Email:

nurfitriyah@unram.ac.id.
Abstract: This service aims to make savings and loan cooperatives in the Welfare Environment easy to access bank credit through the implementation of a computerbased accounting information system in the process of preparing financial reports and this becomes a pilot model in developing financial statement applications for other types of cooperatives in the city of Mataram. This service method consists of: 1) the first stage where the creation of a computer application for managing the financial statements of savings and loan cooperatives. With this application, it will be easier for administrators to make cooperative financial reports. 2) the second stage, where computer application training for the management of cooperative financial reports. This assistance is carried out in one of the houses of the cooperative management in the Perumnas Welfare environment using their respective laptops and also the assistants visit one of the administrators in their respective homes to be given assistance. This assistance is carried out for a day with 9 cooperative managers from 9 RTs in the Welfare Environment. This mentoring activity went smoothly. All participants enthusiastically followed the event to the end. Participants also considered that this assistance was important and indispensable for cooperative management. Participants hope to be followed up by providing more assistance so that the management can apply the preparation of cooperative financial reports using excel.

Keywords: assistance; application; cooperative financial reports

Abtrak: Pengabdian ini bertujuan agar koperasi simpan pinjam di Lingkungan Kesra mudah dalam mengakses perkreditan bank melalui implementasi sistem informasi akuntansi berbasis komputer dalam proses penyusunan laporan keuangan dan hal tersebut menjadi model percontohan dalam pengembangan aplikasi laporan keuangan bagi jenis koperasi lainnya di kota Mataram. Metode pengabdian ini terdiri dari : 1) tahap Pertama dimana pembuatan aplikasi computer untuk pengelolaan laporan keuangan koperasi simpan pinjam. Dengan adanya aplikasi ini akan memudahkan pengurus membuat laporan keuangan koperasi. 2) tahap Kedua, dimana pelatihan aplikasi computer untuk pengelolaan laporan keuangan koperasi. Pendampingan ini dilaksanakan di salah satu rumah pengurus koperasi di lingkungan Kesra Perumnas dengan menggunakan laptop masingmasing dan juga pendamping mendatangi satu-satu pengurus di rumah masingmasing untuk diberikan pendampingan. Pendampingan ini dilaksanakan selama sehari dengan 9 orang pengurus koperasi yang berasal dari 9 RT yang ada di Lingkungan Kesra. Kegiatan pendampingan ini berjalan dengan lancar. Semua peserta antusias mengikuti acara hingga selesai. Peserta juga menilai bahwa pendampingan ini penting dan sangat diperlukan bagi pengurus koperasi. Peserta berharap ditindaklanjuti dengan melakukan pendampingan lagi sehingga pengurus dapat mengaplikasikan pembuatan laporan keuangan koperasi dengan menggunakan excel.

Kata Kunci: pendampingan; aplikasi; laporan keuangan koperasi 


\section{PENDAHULUAN}

Bimbingan Teknis untuk pengurus koperasi perlu dilakukan untuk menyesuaikan dengan Peraturan Menkop dan UKM Nomor 8 Tahun 2018. Mengapa, karena waktu para pelaku koperasi mendapatkan dana bergulir peraturan itu belum diterbitkan. Jadi ketika akan mengajukan lagi, aturan pun berbeda sehingga perlu ada penyesuaian agar proposal yang diajukan pun sudah sesuai dan memenuhi persyaratan. Peraturan Menkop dan UKM Nomor 8 Tahun 2018 dihadirkan untuk mempermudah prosedur dan persyaratan pengajuan pinjaman ke LPDB-KUMKM. Dengan kemudahan ini, akan juga memudahkan juga para calon mitra mengajukan dana bergulir. Berdasarkan peraturan itu pula, para pelaku KUMKM yang sudah mendapatkan bantuan dana bergulir boleh mengajukan lagi proposal peminjaman. LPDB-KUMKM mensyaratkan ada 13 persyaratan administrasi (kelengkapan dokumen) yang harus dipenuhi koperasi. Seperti akte pendirian dan pengesahannya, hingga laporan keuangan.

Menurut data dari Kementerian Koperasi dan Usaha Kecil Dan Menengah Republik Indonesia hingga 31 Desember 2019 telah tercatat 123.048 unit koperasi aktif di Indonesia. Untuk NTB sendiri dari jumlah koperasi aktif sebanyak 2.396 unit hanya 1.187 unit saja yang mampu melaksanakan RAT, jika di prosentasekan jumlah ini setara dengan $49 \%$ dari jumlah keseluruhan koperasi yang ada di Prov.NTB www.depkop.go.id/data-koperasi

Pelaksanaan RAT bagi koperasi adalah wajib hukumnya, jika tidak dilaksanakan secara terus menerus selama 3 tahun maka koperasi bersangkutan dapat di Non-Aktifkan atau dibubarkan. Dalam RAT juga dibahas tentang pengangkatan dan pemberhentian pengurus koperasi,Pembagian SHU dan pemeriksaan (audit) laporan keuangan koperasi oleh badan pengawas koperasi. Laporan keuangan koperasi juga merupakan salah satu indikator penting dalam menilai kualitas koperasi layak-tidaknya diberikan modal oleh Stakeholder. Dalam hal ini memilih koperasi simpan pinjam karena usaha utama nya adalah simpan pinjam sehingga laporan keuangan yang dimiliki harus berkualitas agar stakeholder tidak ragu untuk menginvestasikan uangnya pada koperasi. Oleh karena itu pengabdian ini memberikan pelatihan penguasaan teknologi komputer kepada pengurus koperasi agar mampu mengembangkan usahanya menjadi lebih maju.

Selama ini, pengurus koperasi membuat laporan keuangan secara manual dan terkadang data itu tidak dilaporkan pada akhir tahun. Sistem pelaporan keuangan yang kurang bagus itu menjadi salah satu kendala mengakses modal di perbankan. Sejumlah koperasi juga sudah memanfaatkan teknologi informasi untuk mengembangkan usaha, dengan menguasai teknologi komputerisasi, para pengurus koperasi bisa mengembangkan berbagai jenis usaha. Sistem informasi akuntansi dapat mengurangi kesalahan pengelolaan data akuntansi sehingga menghasilkan informasi akuntansi yang berkulitas untuk pengambilan keputusan Informasi yang dihasilkan ini berasal dari adanya data akuntansi, data akuntansi terbentuk dari adanya proses akuntansi yang dimulai dari pencatatan transaksi, penggolongan masing-masing transaksi dan peringkasan-peringkasan yang menghasilkan laporan keuangan (Hapsari, 2005). Informasi tersebut dapat mendukung manajemen dalam pengambilan keputusan. Informasi yang tersedia dan digunakan manajemen sangat membantu para manajer dalam menyelesaikan tugasnya, sehingga diharapkan kinerja akan meningkat (Anggraini, 2011).

Lingkungan Kesra Tanjung Karang Permai belum ada template aplikasi excel koperasi untuk penyusunan laporan keuangan pada koperasi simpan pinjam sehingga tim pengabdian membuatkan aplikasi laporan keuangan dengan menggunakan program excel dengan harapan para pengelola koperasi bisa membuat laporan SHU dan Neraca dengan baik dan benar sehingga bisa memperoleh tambahan dana dari pihak eksternal, misalnya pinjaman bagi usaha mikro dari bank dan bisa mengembangkan usahanya sehingga modal koperasi bisa meningkat dan menyejahterakan anggotanya 
dan menjadi model percontohan dalam pengembangan aplikasi laporan keuangan bagi jenis koperasi lainnya di kota Mataram.

\section{METODE}

Untuk pemecahan permasalahan mitra terkait dengan pembuatan aplikasi laporan keuangan dengan menggunakan ecxel maka pelaksanan pengabdian ini ada dua tahap, antara lain :

1) Tahap Pertama

Pembuatan aplikasi computer untuk pengelolaan laporan keuangan koperasi simpan pinjam.

Dengan adanya aplikasi ini akan memudahkan pengurus membuat laporan keuangan koperasi.

2) Tahap Kedua

Pelatihan aplikasi computer untuk pengelolaan laporan keuangan. Pelatihan ini dilaksanakan di salah satu rumah pengurus koperasi di lingkungan Kesra Perumnas dengan menggunakan laptop masing-masing. Dalam pelatihan ini metodenya ceramah, latihan dan diskusi.

Sasaran pembuatan dan pelatihan aplikasi komputer penyusunan laporan keuangan pada koperasi simpan pinjam di kota lingkungan Kesra Tanjung Karang Permai adalah pengurus koperasi. Kenapa pengurus karena pengurus koperasi yang akan melakukan penyusunan laporan keuangan koperasi. Jumlah koperasi di lingkungan Kesra Tanjung Karang Permai sebanyak 9 koperasi. Sehingga total peserta pelatihan ini sebanyak 9 orang pengurus koperasi.

Tabel 1. Analisis Situasi

\begin{tabular}{|c|c|c|}
\hline No & Item & Keterangan \\
\hline 1 & Waktu & Bulan Juli / Agustus 2020 \\
\hline 2 & Pemateri & $\begin{array}{l}\text { a. Nur Fitriyah : Teori laporan keuangan koperasi } \\
\text { b. Herlina Pusparini : Teori laporan keuangan koperasi } \\
\text { c. Nurabiah : Praktek membuat laporan keuangan koperasi } \\
\text { dengan menggunakan ecxel }\end{array}$ \\
\hline 3 & Materi & Bisa dilihat di Lampiran 2. Gambaran Ipteks \\
\hline 4 & Bahan/Alat & $\begin{array}{ll}\text { a. } & \text { Whiteboard } \\
\text { b. } & \text { Infocus/LCD } \\
\text { c. } & \text { Laptop }\end{array}$ \\
\hline 5 & Jumlah koperasi & 9 Koperasi simpan pinjam skala kecil \\
\hline 6 & Jumlah peserta & 9 orang pengurus (masing-masing koperasi 1 pengurus) \\
\hline 7 & Jenis koperasi & Simpan Pinjam \\
\hline 8 & Evaluasi & Evaluasi akan dilakukan bulan September 2020 \\
\hline
\end{tabular}

\section{HASIL DAN PEMBAHASAN}

Hasil kegiatan yang telah dilakukan dalam pengabdian ini adalah sebagai berikut :

A. Tahap Perencanaan Pengabdian

Pada tahap ini, berdasarkan investigasi awal, tim pengabdi menganalisis mengenai kebutuhankebutuhan apa yang digunakan dalam pengabdian ini. Karena ini pendampingannya berupa pembuatan laporan SHU dan laporan keuangan koperasi dengan menggunakan excel, sehingga dibutuhkan persiapan-persiapan seperti perlengkapan dan peralatan seperti kertas, alat-alat tulis, dan laptop. Kebetulan ada beberapa pengurus selama membuat laporan SHU tidak menggunakan laptop untuk menghitung SHU hanya menggunakan kalkulator secara manual.

B. Tahap Pelaksanaan Pengabdian

Pendampingan ini dilaksanakan di salah satu rumah pengurus koperasi di lingkungan Kesra Perumnas dan juga pendamping mendatangi satu-satu pengurus di rumah masing-masing untuk diberikan pendampingan. Pendampingan ini dilaksanakan selama sehari dengan 9 orang pengurus 
koperasi yang berasal dari 9 RT yang ada di Lingkungan Kesra. Pengabdian ini dilaksanakan tanggal 20 Agustus 2020. Pengabdian ini menfokuskan pendampingan dalam hal pembuatan SHU dan laporan keuangan koperasi dengan menggunakan aplikasi yang sudah dibuat di excel. Aplikasi excel ini merupakan adaptasi dari aplikasi yang dibuat oleh Irfan Fathoni, Indah Dwi Haryati, dan Apris Tri Maryono (2013). Aplikasi yang dibuat sudah ada templatenya masing-masing di excel sehingga memudahkan pengurus menginput transaksi-transaksi yang terjadi di koperasi sehingga akan menghasilkan SHU dan laporan keuangan koperasi yang otomatis. Adapun template aplikasi excel tersebut terdiri dari antara lain : 1) Nama perusahaan dan periode 2) Penganggung jawab laporan 3) Daftar rekening 4) Jurnal penerimaan kas 5) Jurnal pengeluaran kas 6) Jurnal Umum 7) Buku besar 8) buku pembantu 9) Neraca dan 10) Perhitungan SHU. Contoh menu-menu di aplikasi tersebut bisa dilihat di gambar 1.

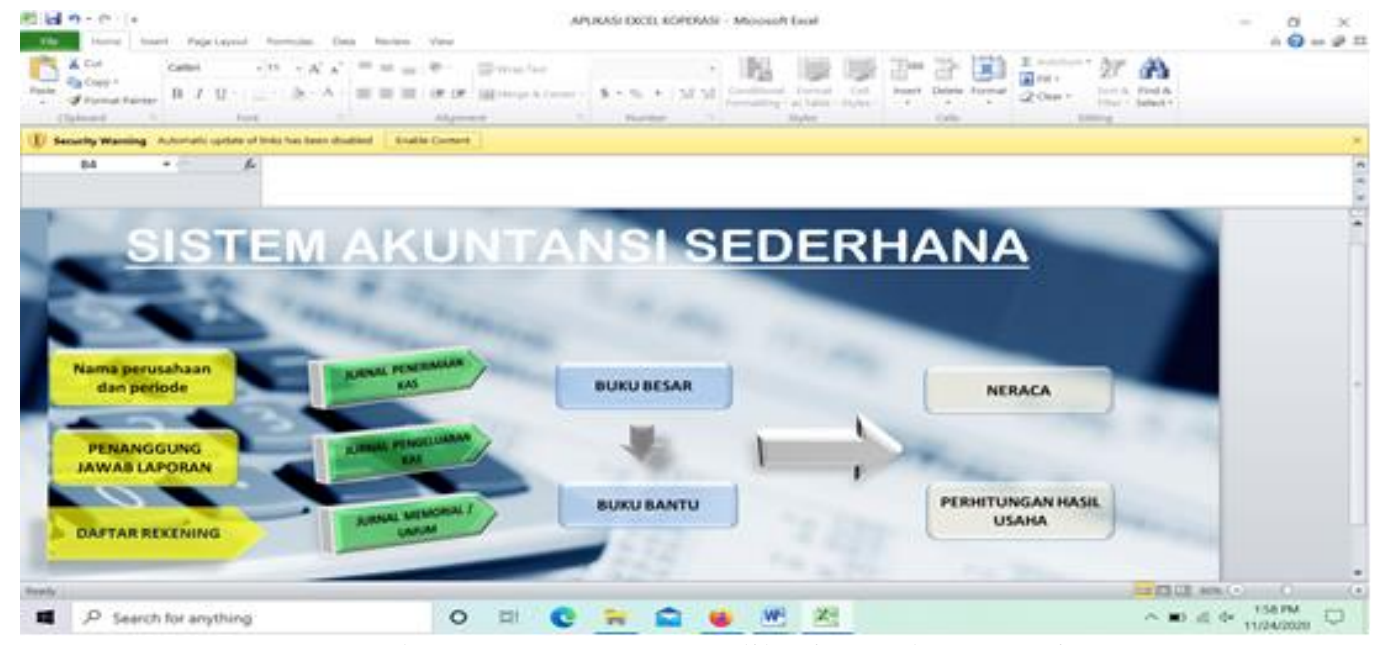

Gambar 1. Menu-menu Aplikasi Excel Koperasi
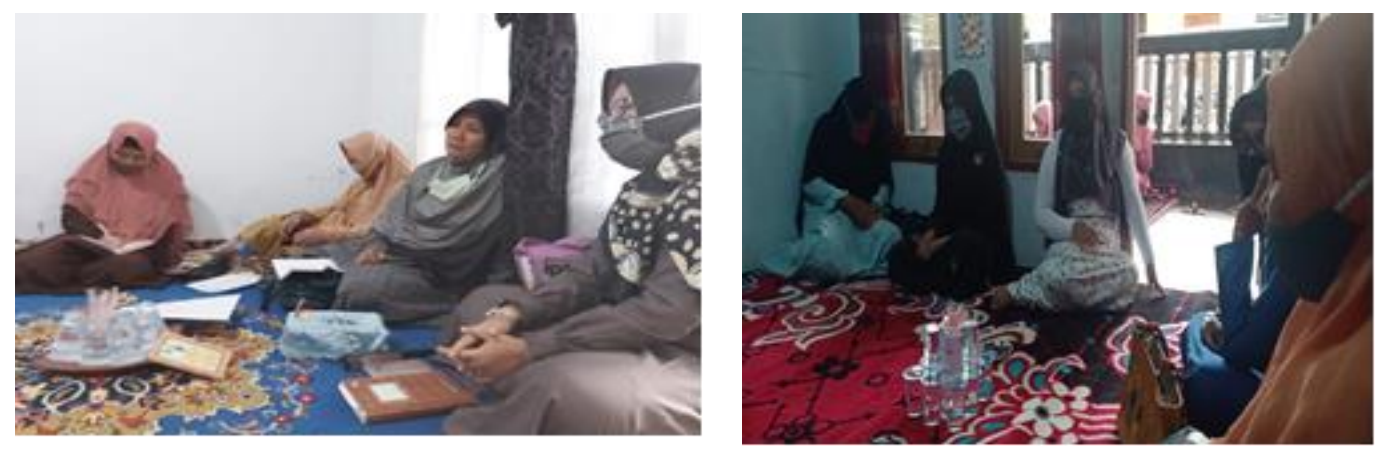

Gambar 2. Foto Pengabdian

Dengan melihat kondisi beberapa pengurus koperasi Lingkungan Kesra Tanjung Karang Permai yang secara usia sudah lanjut maka Tim pengabdi melakukan pendapingan secara berkelanjutan dan kebetulan salah satu tim pengabdi tinggal di lingkungan Kesra sehingga memudahkan untuk memberikan pendampingan secara terus menerus. Permai

Ada beberapa foto pada saat pelaksanan pengabdian di Lingkungan Kesra Tanjung Karang

\section{Tahap Evaluasi Kegiatan}

Adapun pada tahap evaluasi kegiatan dilakukan pada bulan September-November 2020. Halhal yang jadi tolak ukur pada tahap ini adalah sebagai berikut : 
Tabel 3. Tolak Ukur Pelaksanaan

\begin{tabular}{|c|c|c|}
\hline Tujuan & Indikator Capaian & Tolak Ukur \\
\hline $\begin{array}{l}\text { Pembuatan aplikasi computer } \\
\text { untuk penyusunan laporan } \\
\text { keuangan, dimana aplikasinya } \\
\text { dengan menggunakan program } \\
\text { Microsoft Excel }\end{array}$ & $\begin{array}{l}\text { Tim pengabdi bisa membuat } \\
\text { atau mengadaptasi aplikasi } \\
\text { excel koperasi yang mudah } \\
\text { digunakan oleh peserta } \\
\text { dimana menu-menunya } \\
\text { menggunakan bahasa yang } \\
\text { mudah dan pencarian } \\
\text { menunya tidak ribet dan } \\
\text { menu-menu tersebut tinggal } \\
\text { satu klik }\end{array}$ & $\begin{array}{l}\text { Peserta mampu } \\
\text { menggunakan aplikasi excel } \\
\text { koperasi dengan mudah } \\
\text { tanpa berpikir panjang }\end{array}$ \\
\hline \begin{tabular}{lll}
\multicolumn{2}{l}{ Agar pengelola koperasi lebih } \\
memahami & aplikasi laporan \\
keuangan & akan diberikan \\
pelatihan & &
\end{tabular} & 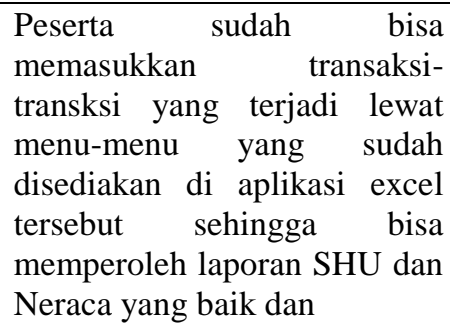 & $\begin{array}{l}\text { Peserta sudah menggunakan } \\
\text { aplikasi excel koperasi ini } \\
\text { karena sudah berulang- } \\
\text { ulang kali menggunakannya } \\
\text { dan kalaupun pengurus } \\
\text { ganti tinggal menggunakan } \\
\text { template tersebut dengan } \\
\text { mudah }\end{array}$ \\
\hline $\begin{array}{l}\text { Agar pengelola koperasi lebih } \\
\text { mengerti dan mampu } \\
\text { mengaplikasikan pembukuan } \\
\text { laporan keuangan, sehingga } \\
\text { dapat memberikan manfaat bagi } \\
\text { koperasi untuk memperoleh } \\
\text { tambahan dana dari pihak } \\
\text { eksternal, misalnya pinjaman } \\
\text { bagi usaha mikro dari bank dan } \\
\text { mengembangkan usahanya. }\end{array}$ & $\begin{array}{l}\text { Setelah peserta menghasilkan } \\
\text { laporan SHU dan neraca yang } \\
\text { baik dan benar, bisa } \\
\text { menambah modal dengan } \\
\text { melakukan pinjaman dana dari } \\
\text { pihak eksternal khususnya } \\
\text { perbankan }\end{array}$ & $\begin{array}{lcr}\text { Peserta } & \text { sudah } & \text { bisa } \\
\text { menigkatkan } & \text { modal } \\
\text { koperasi } & \text { lewat } & \text { pihak } \\
\text { eksternal } & \text { selain } & \text { anggota } \\
\text { koperasi } & & \end{array}$ \\
\hline
\end{tabular}

\section{KESIMPULAN DAN SARAN}

\section{Kesimpulan}

Melalui pendampingan ini diharapkan para peserta (pengurus) koperasi di Lingkungan Kesra sudah bisa membuat laporan SHU dan Neraca dengan menggunakan aplikasi excel koperasi sehingga bisa mempertanggungjawabkan kepada anggota koperasi dan mendapatkan dana dari pihak ekternal khususnya perbankan pada akhirnya akan meningkatkan modal bagi koperasi tersebut.

Ada beberapa faktor-faktor pendorong dan penghambat pelaksanaan pendampingan pembuatan laporan SHU dan Neraca dengan menggunakan aplikasi excel koperasi bagi pengurus koperasi di Lingkungan Kesra, yaitu: (a) faktor pendorong terdiri dari terjalinnya kerjasama antara tim pengabdian dengan ibu pengurus koperasi dan selama pelaksanaan kegiatan pendapingan ini seluruh peserta memberikan apresiasi yang baik. Peserta secara aktif mengikuti kegiatan ini dari awal hingga akhir, hal ini ditunjukkan dengan banyaknya peserta yang bertanya. (b) faktor penghambat yaitu sulitnya menentukan jadwal pertemuan antara tim pengabdian dengan ibu-ibu pengurus koperasi karena kesibukan dalam menjalankan kegiatan sehari-hari mereka dan ditambah lagi di masa pendemi Covid-19 para peserta dan tim pengabdi agak takut melakukan pertemuan. Tetapi secara keseluruhan tidak ada hambatan yang terlalu teknis maupun administratif.

\section{Saran}

Mengingat peserta yang mendapat kesempatan mengikuti pelatihan ini terbatas dan bukanlah hal yang mudah maka perlu adanya upaya untuk melanjutkan kegiatan pendampingan serta perlu adanya pembimbingan secara berkelanjutan untuk mendapatkan hasil yang optimal. Disamping itu untuk kegiatan selanjutnya diperlukan dana yang lebih besar. 


\section{Ucapan Terima Kasih}

Keberhasilan pelaksanaan kegiatan ini tidak terlepas dari partisipasi, dukungan dan bantuan moral, finansial maupun fisik dari banyak pihak. Oleh karena itu, kami mengucapkan ucapan terima kasih kepada Dekan Fakultas Ekonomi dan Bisnis Universitas Mataram, Bapak Dr. Muaidy Yasin, MS; Kepala Bappeda Kota Mataram, Bapak Ir. H. Amiruddin, M.Si.; Ketua Dharma Wanita Unit Bappeda Kota Mataram, Ibu Hj. Baiq Lily C. Amiruddin, SH; dan terlebih lagi kepada peserta kegiatan.

\section{DAFTAR PUSTAKA}

Anggaraini, Tresye Yeni. 2011. Pengaruh Sistem Informasi Akuntansi Terhadap Kinerja Manajerial Pada Perusahaan Ritel di Surabaya. Sekolah Tinggi Ilmu Ekonomi Perbanas. Surabaya.

Dininovia, 2012. Masalah -masalah yang timbul dalam koperasi indonesia saat ini yang diakses pada 9 januari 2013 http://dininovia.wordpress.com /2012/01 /08/ masalah- masalah-yang-timbuldalam-koperasi-indonesia-saat-ini/

Hapsari, Ulfi. 2005. Penerapan Sistem Informasi Akuntansi dan Pengeluaran Kas Pada Unit Usaha Toko di KPRI Serba Usaha Migas Cepu. Fakultas Ilmu Sosial Universitas Negeri Semarang. Semarang.

Sumarso. SR, Akuntansi Suatu Pengantar, edisi 4, penerbit: Rineka Cipta, Jakarta www.depkop.go.id/data-koperasi diakses tanggal 10 Februari 2020. 